
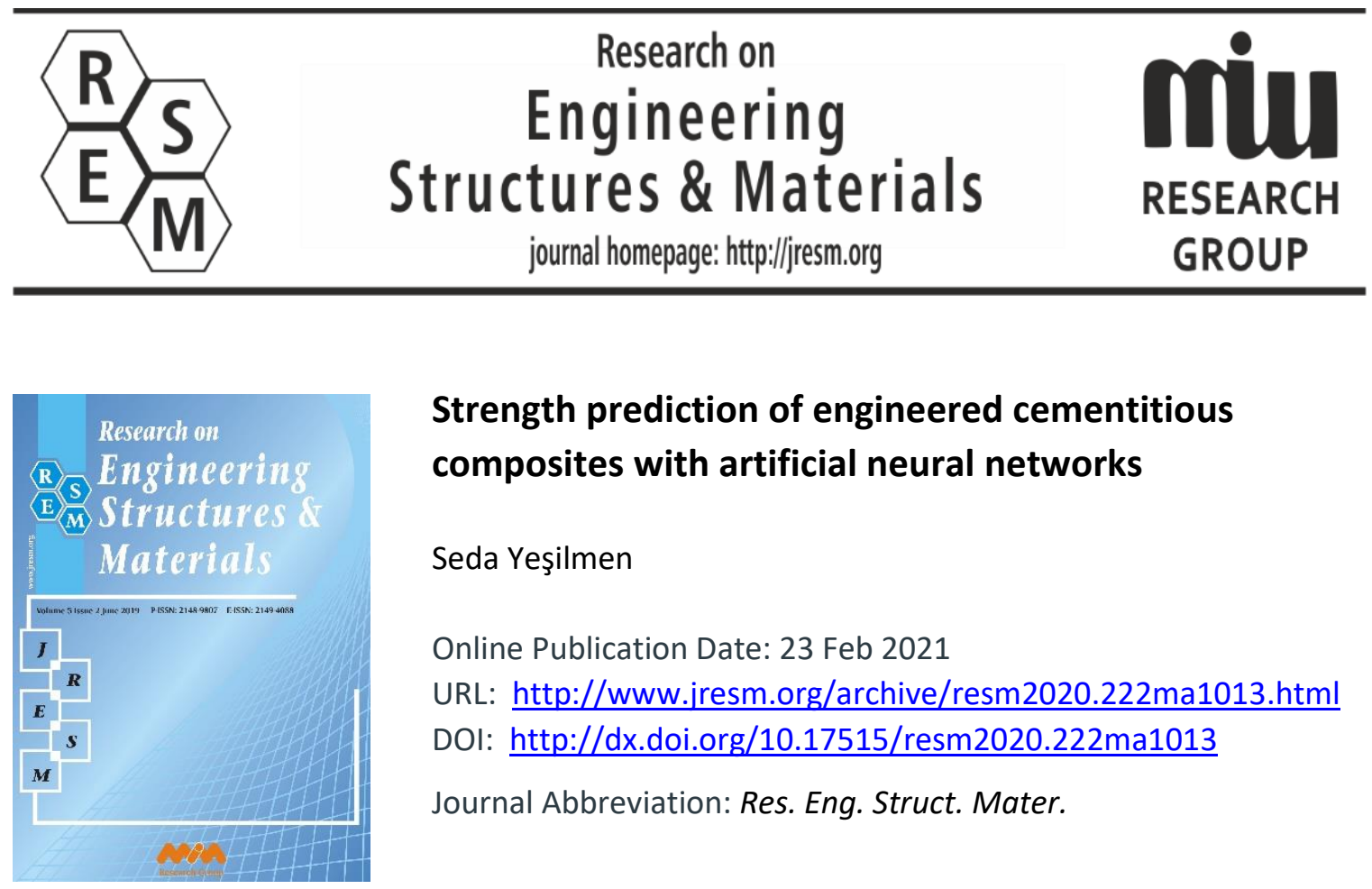

\title{
Strength prediction of engineered cementitious composites with artificial neural networks
}

Seda Yeşilmen

Online Publication Date: 23 Feb 2021

URL: http://www.jresm.org/archive/resm2020.222ma1013.html

DOI: http://dx.doi.org/10.17515/resm2020.222ma1013

Journal Abbreviation: Res. Eng. Struct. Mater.

\section{To cite this article}

Yeşilmen S. Strength prediction of engineered cementitious composites with artificial neural networks. Res. Eng. Struct. Mater., 2021; 7(2): 173-182.

\section{Disclaimer}

All the opinions and statements expressed in the papers are on the responsibility of author(s) and are not to be regarded as those of the journal of Research on Engineering Structures and Materials (RESM) organization or related parties. The publishers make no warranty, explicit or implied, or make any representation with respect to the contents of any article will be complete or accurate or up to date. The accuracy of any instructions, equations, or other information should be independently verified. The publisher and related parties shall not be liable for any loss, actions, claims, proceedings, demand or costs or damages whatsoever or howsoever caused arising directly or indirectly in connection with use of the information given in the journal or related means.

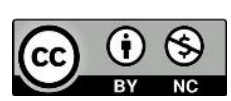

Published articles are freely available to users under the terms of Creative Commons Attribution - NonCommercial 4.0 International Public License, as currently displayed at here (the "CC BY - NC"). 


\section{Research on Engineering Structures \& Materials \\ journal homepage: http://jresm.org}

Research Article

\section{Strength prediction of engineered cementitious composites with artificial neural networks}

Seda Yeşilmen

Department of Civil Engineering, Cankaya University, Ankara, Turkey

\begin{tabular}{ll} 
Article Info & Abstract \\
\hline $\begin{array}{l}\text { Article history: } \\
\text { Received 13 Oct 2020 }\end{array}$ & $\begin{array}{l}\text { Engineered Cementitious composites (ECC) became widely popular in the last } \\
\text { decade due to their superior mechanical and durability properties. Strength } \\
\text { prediction of ECC remains an important subject since the variation of strength } \\
\text { Revith 15 Jan 2021 }\end{array}$ \\
$\begin{array}{ll}\text { Accepted 21 Feb 2021 } \\
\text { components and corresponding strengths of various ECC designs are obtained } \\
\text { from the literature and ANN models were developed to predict compressive and } \\
\text { Keywords: }\end{array}$ & $\begin{array}{l}\text { flexural strength of ECCs. Error margins of both models were on the lower side } \\
\text { of the reported error values in the available literature while using data with the } \\
\text { highest variability and noise. As a result, both models claim considerable } \\
\text { prediction; Compressive } \\
\text { Strength }\end{array}$
\end{tabular}

(C) 2021 MIM Research Group. All rights reserved.

\section{Introduction}

Prediction of concrete strength has been a popular area among concrete technology topics $[1,2]$. Accuracy of the strength prediction is more critical for repair and retrofitting materials such as Engineered Cementitious Composites (ECC). ECC is a strong alternative for conventional materials for repair, retrofitting and infrastructural applications. They offer significant improvements on various mechanical and durability properties of concrete especially flexural strength. PVA fibers bridging microcracks prohibits formation of large cracks consequently ultimate tensile strain capacity and tensile strength values reported up to $4.7 \%$ and $6 \mathrm{MPa}$ respectively in the literature [3-6].

The major factor determining the compressive strength of cementitious composites is mix design, the components of which widely used in strength prediction of cementitious composites. Artificial neural networks (ANN) is a widely used method for strength prediction of concrete and cementitious composites [7,8]. ANN is used to construct mapping functions for predicting strength and it is a powerful tool for solving very complex problems. Multilayer perceptron (MLP) neural networks are standard neural network models with an input layer representing cementitious composite mix design components, hidden layers with computation neurons, and an output layer containing one neuron representing strength prediction.

Previous studies on concrete mixtures are known to yield high accuracies especially when data is from a single batch or from a single production location [9]. However, when ANN models were trained with data from various sources, test errors increased even with a powerful tool such as ANN $[10,11]$.

Predictive performance of ANN is dependent on various factors and can be quite different for various types of cementitious composites. There are lots of other contributing factors

Corresponding author: syesilmen@cankaya.edu.tr

orcid.org/0000-0002-2046-3841

DOI: http://dx.doi.org/10.17515/resm2020.222ma1013

Res. Eng. Struct. Mat. Vol. 7 Iss. 2 (2021) 173-182 
other than mix design parameters when predicting strength, such as age, curing conditions, and handling practices, etc. Most of these factors are not included in the training data because they are categorical parameters and cannot be used in a regression problem directly. These categorical parameters considered to be one of the reasons for decreasing accuracies in strength prediction. Considering cementitious composites such as ECC, there are even more categorical parameters such as fiber type, mineral admixture type, etc. Individual ANN models were developed for different fiber types or different admixture types to be able to obtain acceptable accuracies when predicting ECC strength in the literature [12,13]. These models yield very high accuracies, but they are both specific to one type of ECC and the test results are obtained from a single batch of ECC which has very low noise and variability in the input data. [11-14]

This study aims to incorporate several categorical parameters for strength prediction of ECC mixtures, so a single ANN model can be developed for very different mixture characteristics. Additionally the models will be applicable to a range of different ECC mixes unlike previous studies. Compressive strength of any cementitious composite is the most important materials property since they are designed to mainly work in compression as a building material. In the literature compressive strengths in the range of 25 to $115 \mathrm{MPa}$ were reported [3-6,15]. Considering ECC gained its popularity mostly due to its high flexural strength capacity, two strength categories namely flexural and compressive strength were predicted using the data obtained from literature. Two single ANN models were developed to predict compressive and flexural strengths of ECC with different chemical and mineral admixture types, fiber types, age, specimen geometry and dimensions.

\section{Materials and Methods}

Artificial neural networks (ANNs) use back-propagation (BP) algorithm, which adjusts connection weights $(\mathrm{w})$ and bias values (b) during training. The forward propagation in ith output layer can be expressed as:

$$
\begin{aligned}
& z_{j}^{[i]}=\sum_{k}^{n} w_{j k}^{[i]} x_{k}^{[i-1]} \\
& a_{j}^{[i]}=f\left(z_{j}^{[i]}\right)
\end{aligned}
$$

where $\mathrm{i}$ is the layer of the neuron, $\mathrm{n}$ is the number of neurons in the previous layer, wjk is the weight associated to jth neuron applied to the kth neuron from the previous layer, $x \mathrm{k}$ is the output of neuron $\mathrm{k}, \mathrm{zj}$ is the output of neuron $\mathrm{j}$ for layer $\mathrm{i}$, and aj activation function applied to zj for layer i. After initializing weights, an optimization method is used to minimize the selected cost function.

Two hidden layers were used in the ANN model for this study. ANN model was implemented using Tensorflow library in the medium of python. Activation function was selected to be sigmoid for all layers except output layer. Sigmoid function is often used in ANN to introduce nonlinearity in a model. It simply converts the output of the neuron to a value in the range of $(0,1)$ so that activated output that will be fed to the next set of perceptrons will be 1 at most when the output is too large and 0 if output is too small [16].

Gradient descent-based algorithms are used commonly in ANN models. Adam Optimization algorithm was selected to be used in the ANN model since it showed better convergence compared to other gradient descend based algorithms in the literature. Adam optimization is based on the idea of adaptive moment estimation, learning rate decay is implemented using exponential moving average of the gradient. This algorithm is reported 
to be efficient and convenient for a wide range of optimization problems in the field of machine learning [17].

Total dataset was divided into $80 \%$ and $20 \%$ to use as training and test data, respectively. Training and testing data were separated using train_test_split function of sklearn library. Train_test_split function splits arrays or matrices into random training and testing subsets. This function also shuffles the data before splitting which can be critical during training. Validation data was not used, instead cross validation was performed for hyper parameter tuning. Cross validation method is commonly used when training data is relatively small. In cross validation method, training data is split into 5 subsets, and 4 of those subsets are used to train the model with a specific hyperparameter combination, as one of the subsets kept as test data. For categorical features, one_hot encoding was applied using get_dummies function in pandas library.

A total of 214 different ECC mix designs for compressive strength and 147 for flexural strength are obtained from various sources [3,13,18-36]. A total of 13 parameters were incorporated which were readily available from the literature namely; age, cement content, cement type, fiber content, water content, aggregate content, and chemical admixture content, mineral admixture type and content, specimen geometry, specimen dimensions, Calcium and silica content of mineral admixtures. Since flexural specimens were always prismatic, specimen geometry parameter was not included which reduced the total parameters to 12 for flexural strength model. Categorical variables are given in Table 1. The categories for each categorical variable listed in this table shows the categories that are found in the database used. All the non-categorical parameters were defined for $1 \mathrm{~m} 3$ of ECC. Minimum and maximum values of non-categorical parameters for the dataset used in this study are given in Table 2.

There is no specific standard that governs the specimen preparation for ECC. Typically mixtures were prepared following a typical ECC mixing procedure. The procedure involves mixing the dry ingredients first and adding liquid ingredients such as superplasticizers, water, admixtures etc. The mixing operation is performed at various speeds to ensure homogeneous fiber dispersion [18-36]. Following demolding after 24 hours, specimens usually cured sealed in plastic sheets until the testing date. Compressive and flexural strength testing followed related ASTM standards $[37,38]$

Table 1. Categorical Parameters

\begin{tabular}{cc}
\hline Parameters & Categories \\
\hline Cement type & CEM I 52.5R, Type I OPC, CEM I 42.5N \\
Mineral admixture & Limestone powder, Fly ash, Blast furnace slag, Silica fume, \\
type & Natural pozzolan \\
Specimen geometry & Compression: Cylinder, Prism \\
Specimen dimensions & Flexure: Prism \\
& Compression: $40 * 40 * 40,50 * 50 * 50,75 * 150$ \\
& Flexure: $40 * 40 * 160,100 * 100 * 400,75 * 50 * 360$
\end{tabular}


Table 2. Dataset properties

\begin{tabular}{cccc}
\hline \multicolumn{2}{c}{ Dataset for compressive strength of ECC } & & \\
\hline Parameter & Unit & Min. & Max. \\
Age & Day & 7 & 180 \\
Cement content & $\mathrm{kg} / \mathrm{m}^{3}$ & 275 & 1000 \\
Fiber content & $\%$ by volume & 0.25 & 2 \\
Water content & $\mathrm{kg} / \mathrm{m}^{3}$ & 74 & 638 \\
Chemical admixture content & $\mathrm{kg} / \mathrm{m}^{3}$ & 1.8 & 30 \\
Mineral admixture content & $\mathrm{kg} / \mathrm{m}^{3}$ & 0 & 2550 \\
Calcium content of mineral admixture & $\%(\mathrm{by} \mathrm{mass})$ & 0 & 35.1 \\
Silica content of mineral admixture & $\%(\mathrm{by} \mathrm{mass})$ & 0.3 & 78.1 \\
Compressive strength & $\mathrm{MPa}$ & 8.2 & 95.1 \\
Flexural strength & $\mathrm{MPa}$ & 0.3 & 23.75 \\
\hline
\end{tabular}

\section{Results and Discussion}

A grid search algorithm was performed to establish learning rate and model architecture. Grid search algorithm was employed for both training and validation data. As mentioned in the previous chapter cross validation method is used to create validation data. Different node numbers were used in the range of 3 to 9 for each layer. Additionally, a learning rate range of 0.001-0.009 was also included in the search space. Range values for learning rates and node numbers were decided based on the literature [11-14]. ANN also known to be sensitive to weight initialization. The initial set of weights can cause the algorithm to be stuck in local minima eliminating the chance to find the global solution. Consequently, each architecture was run 10 times for each learning rate and the average values were recorded so the effect of weight initialization can be removed. In Table 3 learning rates are reported for the lowest RMSE yielding model after all values are applied in the learning rate range. As can be seen from this table increase in the node numbers did not always translate into a decrease in RMSE values. Final architecture was chosen to be 6 and 7 nodes at first and second hidden layers, respectively with a learning rate of 0.005 . A similar grid search was performed for flexural strength model and the optimum architecture was selected to be 8 and 7 nodes in the first and second hidden layers, respectively. 
Table 3. Grid Search for hyperparameters in compressive strength prediction model

\begin{tabular}{|c|c|c|c|c|c|c|}
\hline Nodes & Nodes & LearningRate & $\begin{array}{c}\text { RMSE } \\
\text { Training }\end{array}$ & $\begin{array}{c}\text { RMSE } \\
\text { Validation }\end{array}$ & $\begin{array}{c}\mathrm{R} 2 \\
\text { Training }\end{array}$ & $\begin{array}{c}\mathrm{R} 2 \\
\text { Validation }\end{array}$ \\
\hline \multirow[t]{7}{*}{4} & 3 & 0.005 & 5.953 & 5.193 & 0.93 & 0.92 \\
\hline & 4 & 0.005 & 5.023 & 4.596 & 0.95 & 0.94 \\
\hline & 5 & 0.004 & 5.248 & 4.748 & 0.94 & 0.93 \\
\hline & 6 & 0.006 & 4.312 & 4.650 & 0.96 & 0.93 \\
\hline & 7 & 0.006 & 4.805 & 4.524 & 0.94 & 0.94 \\
\hline & 8 & 0.006 & 4.712 & 4.309 & 0.95 & 0.94 \\
\hline & 9 & 0.007 & 4.250 & 4.271 & 0.96 & 0.95 \\
\hline \multirow[t]{7}{*}{5} & 3 & 0.007 & 4.337 & 4.329 & 0.96 & 0.94 \\
\hline & 4 & 0.007 & 5.011 & 4.181 & 0.94 & 0.95 \\
\hline & 5 & 0.007 & 4.147 & 4.250 & 0.97 & 0.95 \\
\hline & 6 & 0.007 & 4.629 & 4.342 & 0.96 & 0.94 \\
\hline & 7 & 0.007 & 4.629 & 4.342 & 0.96 & 0.94 \\
\hline & 8 & 0.007 & 4.342 & 3.999 & 0.96 & 0.95 \\
\hline & 9 & 0.007 & 4.776 & 4.227 & 0.95 & 0.94 \\
\hline \multirow[t]{7}{*}{6} & 3 & 0.004 & 4.322 & 4.566 & 0.99 & 0.95 \\
\hline & 4 & 0.006 & 4.119 & 4.329 & 0.99 & 0.95 \\
\hline & 5 & 0.007 & 3.721 & 4.137 & 0.97 & 0.94 \\
\hline & 6 & 0.006 & 3.864 & 3.660 & 0.98 & 0.96 \\
\hline & 7 & 0.005 & 2.881 & 3.899 & 0.99 & 0.96 \\
\hline & 8 & 0.006 & 3.268 & 3.914 & 0.98 & 0.96 \\
\hline & 9 & 0.005 & 3.041 & 3.838 & 0.99 & 0.96 \\
\hline \multirow[t]{7}{*}{7} & 3 & 0.007 & 3.666 & 3.591 & 0.98 & 0.97 \\
\hline & 4 & 0.004 & 3.941 & 4.218 & 0.97 & 0.95 \\
\hline & 5 & 0.004 & 4.376 & 4.209 & 0.98 & 0.95 \\
\hline & 6 & 0.005 & 2.989 & 4.287 & 0.99 & 0.95 \\
\hline & 7 & 0.006 & 3.992 & 3.846 & 0.97 & 0.96 \\
\hline & 8 & 0.007 & 3.911 & 3.886 & 0.99 & 0.96 \\
\hline & 9 & 0.007 & 3.971 & 3.769 & 0.98 & 0.96 \\
\hline \multirow[t]{7}{*}{8} & 3 & 0.005 & 4.005 & 4.209 & 0.98 & 0.95 \\
\hline & 4 & 0.004 & 3.193 & 3.856 & 0.99 & 0.96 \\
\hline & 5 & 0.007 & 3.625 & 3.927 & 0.98 & 0.96 \\
\hline & 6 & 0.005 & 3.014 & 3.542 & 0.99 & 0.97 \\
\hline & 7 & 0.006 & 3.158 & 3.406 & 0.99 & 0.98 \\
\hline & 8 & 0.007 & 2.803 & 4.267 & 0.99 & 0.95 \\
\hline & 9 & 0.006 & 4.064 & 4.067 & 0.98 & 0.96 \\
\hline \multirow[t]{7}{*}{9} & 3 & 0.007 & 3.495 & 3.679 & 0.98 & 0.96 \\
\hline & 4 & 0.005 & 3.497 & 3.577 & 0.98 & 0.97 \\
\hline & 5 & 0.007 & 2.694 & 3.438 & 0.99 & 0.97 \\
\hline & 6 & 0.005 & 4.594 & 3.772 & 0.95 & 0.96 \\
\hline & 7 & 0.004 & 3.938 & 3.671 & 0.97 & 0.98 \\
\hline & 8 & 0.007 & 3.549 & 3.647 & 0.98 & 0.96 \\
\hline & 9 & 0.007 & 3.890 & 3.843 & 0.98 & 0.96 \\
\hline
\end{tabular}




Age
Cement content
Fiber content
Water content
Aggregate content
Chemical admixture content
Mineral admixture content
Calcium content of mineral admixture
Silica content of mineral admixture
Cement type (categorical)
Mineral admixture type (categorical)
Specimen geometry (categorical)
Specimen dimensions (categorical)
$\quad$ Input Layer

Age

Cement conten

Fiber content

Water content

Aggregate content

Chemical admixture content

rure content

Dut Layer

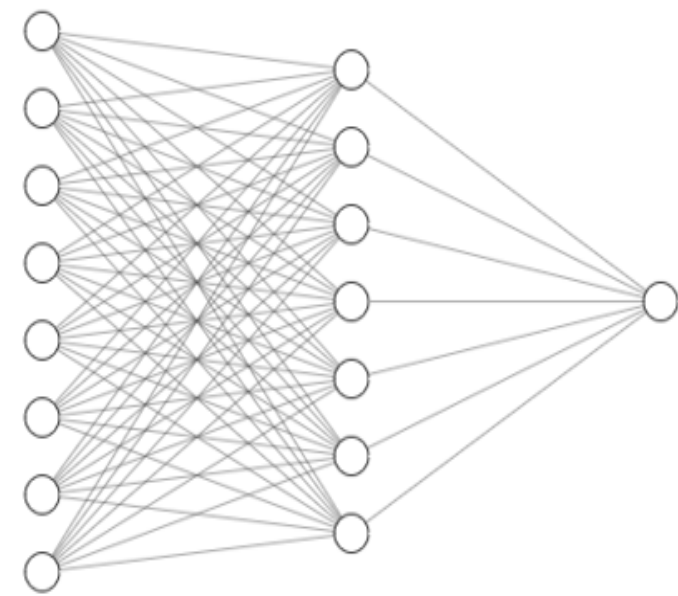

Hidden Layer 1

Hidden Layer 2

Output Layer

Fig. 1 ANN architecture

Architecture for flexural strength model is shown in the Fig 1. As for the Adam Optimizer, beta1 and beta 2 values were chosen as 0.9 and 0.999 which are already default values. Two prediction targets were defined in the output layer; compressive and flexural strength both in MPa as unit resulting in two different models. The average compressive and flexural strengths for the ECC mix designs used were 54.8 and $9.22 \mathrm{MPa}$. Predicted strength versus actual strength values for test data is presented in Figs 2 and 3. There are a couple of strength values that were both over and under predicted in compressive strength model however it can be seen from Fig 2 that majority of the predictions are within the close proximity (deviating around 1-1.5 MPa) of the actual strength value. The RMSE value for the test data is measured as $3.34 \mathrm{MPa}$, which is on the same range with reported values for ECC strength prediction in similar papers [12-14]. For flexural strength values it can be observed from Figure 3 the deviations from actual strength is much less compared to compressive strength. Accordingly, RMSE obtained from test data for flexural strength model is $(0.35 \mathrm{MPa})$ much lower compared to that of compressive strength which is also similar in the reported literature.

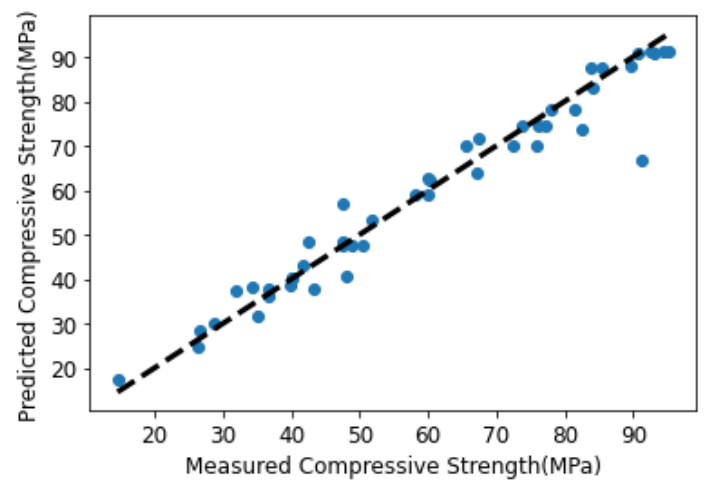

Fig. 2 Predicted compressive strength versus actual strength values for test data. 


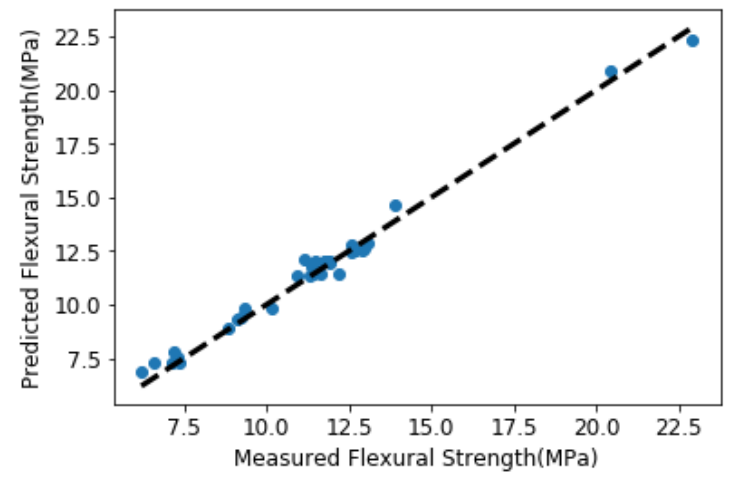

Fig.3 Predicted flexural strength versus actual strength values for test data.

Compared to literature available on strength prediction of ECC, accuracy of both compression and flexural strength models are either in the same range or superior. In addition to high accuracy, strength of a much wider range of ECC types and ages were predicted, mainly due to inclusion of categorical variables [1112,39]. An ANN model trained using data from a single batch of ECC offers very limited applicability. Additionally, high accuracy obtained from such model is most likely achievable by other predictive methods too because of the low variability in the training inputs. However, the literature available on ECC strength prediction is limited to models trained on ECC cast using a single batch with varying only ingredient quantities. Major difference of this work from limited literature works on ECC strength prediction is these ANN models predict strength of ECC with different components obtained from a wide range of data sources with the same accuracy as reported in single batch studies. Accuracy of the model is increased by inclusion of categorical parameters to the model unlike similar model trained in the literature. Predictive scores from test data and final hyperparameters of the ANN models for compressive and flexural strength is given in Table 4 .

Table 4. ANN model results for compressive and flexural strength test data.

\begin{tabular}{ccc}
\hline & Compressive Strength & Flexural Strength \\
\hline MSE & 11.120 & 0.121 \\
RMSE & 3.34 & 0.348 \\
R2 & 0.958 & 0.967 \\
Nodes & 6 and 7 & 8 and 7 \\
Learning rate & 0.005 & 0.006 \\
\hline
\end{tabular}

\section{Conclusions}

Strength prediction of ECC were performed in this study. Data from several papers with a wide range of mix design components were used. Different ECC types and mix designs from different sources in the literature were used which introduced a considerable variance to the dataset. Limited literature available on ECC strength prediction contained data from a single batch of concrete while only quantities of composite components are changing. Relative error values reported for the models trained using low variability data were around $2-10 \%$ for compressive strength and 3-5\% for flexural strength. Two ANN models 
were developed which predicted compressive and flexural strength of ECC. A grid search was also performed for selecting the model architecture and learning rate. Although architectures of the two models were different, a learning rate of 0.06 were proved to be optimal for both models. Number of layers were decided as two since most of the literature on cementitious composites and concrete materials proved to be 2-layer architecture was optimal for strength prediction. Relative errors for the models were $6.5 \%$ and $3 \%$ for compressive and flexural strengths, respectively. In addition, the models were able to predict strength of a wide range of ECC mixes with different specimen shape, specimen geometry, age, mineral and chemical admixture types with high accuracy.

The most important output of this study is the high accuracy obtained with a dataset created using data from various studies. Often when a dataset contains mixed data, accuracy reduces significantly due to increased noise in the data. This study used ECC mix design and strength values from 14 different sources and high accuracy in test data shows both models can be used for strength prediction. It must be noted that inclusion of categorical variables made it possible for the model to learn strength prediction for different ECC types and increased accuracy of the models.

\section{Acknowledgement}

The author wishes to thank Sinan Kefeli for helping with data preparation.

\section{References}

[1] Atici U. Prediction of the strength of mineral-addition concrete using regression analysis. Magazine of Concrete Research, 2010; 62: 585-92. https://doi.org/10.1680/macr.2010.62.8.585

[2] Bhanja S. Sengupta B. Investigations on the compressive strength of silica fume concrete using statistical methods. Cement and Concrete Research, 2002; 32: 1391-4. https://doi.org/10.1016/S0008-8846(02)00787-1

[3] Li VC, Wang S. Wu C. Tensile Strain-Hardening Behavior of Polyvinyl Alcohol Engineered Cementitious Composite (PVA-ECC). Materials Journal, 2001; 98: 483-492 https://doi.org/10.14359/10851

[4] Wang S, Li, VC. Engineered cementitious composites with high-volume fly ash. ACI Materials Journal, 2007; 104: 233-241. https://doi.org/10.14359/18668

[5] Pan Z, Wu C, Liu J, Wang W, Liu J. Study on mechanical properties of cost-effective polyvinyl alcohol engineered cementitious composites (PVA-ECC). ACI Materials Journal, 2015; 78: 397-404. https://doi.org/10.1016/j.conbuildmat.2014.12.071

[6] Yang EH, Yang Y, Li VC. Use of high volumes of fly ash to improve ECC mechanical properties and material greennes. ACI Materials Journal, 2017; 104: 620-628.

[7] Oztas A, Pala M, Ozbay E, Kanca E, Caglar N. Bhatti MA. Predicting the compressive strength and slump of high strength concrete using neural network. Construction and $\begin{array}{llll}\text { Building } & \text { Materials, } & \text { 2006; } & \text { 769-75. }\end{array}$ https://doi.org/10.1016/j.conbuildmat.2005.01.054

[8] Hong-Guang N, Ji-Zong W. Prediction of compress ive strength of concrete by neural networks. Cement and Concrete Research, 2000; 30: 1245-50. https://doi.org/10.1016/S0008-8846(00)00345-8

[9] Peng CH, Yeh IC, Lien LC. Building strength models for high-performance concrete at different ages using genetic operation trees, nonlinear regression, and neural networks. Engineering Composites, 2010; 26: 61-73. https://doi.org/10.1007/s00366-009-0142-5 
[10] Yeh IC. Modeling of strength of high-performance concrete using artificial neural networks. Cement Concrete Research, 1998; 28: 1797-1808. https://doi.org/10.1016/S0008-8846(98)00165-3

[11] Shi L, Lin STK, Lu Y, Ye L, Zhang YX. Artificial Neural Network Based Mechanical and Electrical Property Prediction of Engineered Cementitious Composites. Construction and Building $\quad$ Materials, 2018;174: https://doi.org/10.1016/j.conbuildmat.2018.04.127

[12] Hossain KMA, Anwar MS, Samani SG. Regression and artificial neural network models for strength properties of engineered cementitious composites. Neural Computing Applications, 2018; 29: 631-645. https://doi.org/10.1007/s00521-016-2602-3

[13] Altwair NM, Johari MAM, Hashim SFS. Influence of treated palm oil fuel ash on compressive properties and chloride resistance of engineered cementitious composites. Materials and Structures, 2014; 47: 667-682. https://doi.org/10.1617/s11527-013-0087-4

[14] Liu TY, Zhang P, Wang J, Ling YF. Compressive Strength Prediction of PVA FiberReinforced Cementitious Composites Containing Nano-SiO2 Using BP Neural Network. Materials, 2020; 13: 1215-1229 https://doi.org/10.3390/ma13030521

[15] Ding, Y, Yu K, Mao W. Compressive performance of all-grade engineered cementitious composites: Experiment and theoretical model Construction and Building Materials, 2020; 24:1-11 https://doi.org/10.1016/i.conbuildmat.2020.118357

[16] Basheer IA, Hajmeer M. Artificial neural networks: fundamentals, computing, design, and application. Journal of Microbiological Methods, 2000; 43: 3-31. https://doi.org/10.1016/S0167-7012(00)00201-3

[17] Kingma D, Adam BJ. A Method for Stochastic Optimization. 3rd International Conference on Learning Representations, San Diego, CA, USA, May, 2015.

[18] Choucha S, Benyahia A, Ghrici M, Mansour MS. Effect of natural pozzolan content on the properties of engineered cementitious composites as repair material. Frontiers of Structural and Civil Engineering, 2018; 12: 261-269. https://doi.org/10.1007/s11709017-0394-x

[19] Chung KL, Ghannam M, Zhang C. Effect of Specimen Shapes on Compressive Strength of Engineered Cementitious Composites (ECCs) with Different Values of Water-toBinder Ratio and PVA Fiber. Arabian Journal for Science and Engineering, 2018; 43: 1825-1837. https://doi.org/10.1007/s13369-017-2776-8

[20] Yang EH, Yang Y, Li VC. Use of High Volumes of Fly Ash to Improve ECC Mechanical Properties and Material Greenness. Materials Journal, 2007, 104: 61-64 https://doi.org/10.14359/18966

[21] Li VC, Mishra DK, Wu HC. Matrix design for pseudo-strain-hardening fibre reinforced cementitious composites. Materials and Structures, 1995; 28: 586-595. https://doi.org/10.1007/BF02473191

[22] Sahmaran M, Yucel HE, Demirhan S, Arik MT, Li VC. Combined Effect of Aggregate and Mineral Admixtures on Tensile Ductility of Engineered Cementitious Composites. Materials Journal, 2012; 109: 115-124 https://doi.org/10.14359/51684160

[23] Noushini A, Vessalas K, Samali B. Static Mechanical Properties of Polyvinyl Alcohol Fibre Reinforced Concrete (PVA-FRC). Magazine of Concrete Research, 2014; 66: 12231 https://doi.org/10.1680/macr.13.00320

[24] Pan J, Yuan F, Luo M, Leung K. Effect of composition on flexural behavior of engineered cementitious composites. China Technical Sciences Journal, 2012; 55: 3425-3433. https://doi.org/10.1007/s11431-012-4990-7

[25] Ramanathan P, Baskar I, Muthupriya P, Venkatasubramani R. Performance of selfcompacting concrete containing different mineral admixtures. KSCE Journal of Civil Enginering, 2013; 17: 465-472. https://doi.org/10.1007/s12205-013-1882-8

[26] Şahmaran M, Al-Emam M, Yıldırım G, Şimşek YE, Erdem TK, Lachemi, M. High-earlystrength ductile cementitious composites with characteristicsof low early-age 
shrinkage for repair of infrastructures. Materials and Structures, 2015; 48: 1389-1403. https://doi.org/10.1617/s11527-013-0241-z

[27] Wang S, Li V. Engineered Cementitious Composites with High-volume Fly Ash. ACI Materials Journal, 2007; 104: 1-12 https://doi.org/10.14359/18668

[28] Yao Y, Zhu Y, Yang Y. Incorporation superabsorbent polymer (SAP) particles as controlling pre-existing flaws to improve the performance of engineered cementitious composites (ECC). Construction and Building Materials, 2012; 28: 139-145. https://doi.org/10.1016/j.conbuildmat.2011.08.032

[29] Zhou J, Qian S, Sierra Beltran MG, Ye G, van Breugel K, Li VC. Development of engineered cementitious composites with limestone powder and blast furnace slag. Materials and Structures, 2010; 43: 803-814. https://doi.org/10.1617/s11527-0099549-0

[30] Ge WJ, Cai C, Ji X, Ashour AF, Cao DF. Experimental study of mechanical properties of PVA-ECC under freeze-thaw cycles. Journal of Testing and Evaluation, 2018, 46:1-8 https://doi.org/10.1520/JTE20160145

[31] Ji J, Zhang S, Jiang L, Zhou L, Xu Z, Liu Y, Yu D. Feasibility of developing engineered cementitious composite with high volumes of fly ash using cost-effective PVA fiber. Journal of Testing and Evaluation, 2018; 48: 1188-1205 https://doi.org/10.1520/JTE20170596

[32] Yıldırım G, Öztürk O, Al-Dahawi A, Afşın Ulu A, Şahmaran M. Self-sensing capability of Engineered Cementitious Composites: Effects of aging and loading conditions. Construction and Building Materials, 2020; 231: 1-16 https://doi.org/10.1016/j.conbuildmat.2019.117132

[33] Lee SW, Oh CL, Zain MRM, Yahya NA, Rahman AA. Mechanical performances of green engineered cementitious composites incorporating various types of sand. Key $\begin{array}{llll}\text { Engineering } & \text { Materials, } & \text { 2019, } & \text { 821: }\end{array}$ https://doi.org/10.4028/www.scientific.net/KEM.821.512

[34] Booya E, Gorospe K, Das S, Loh P. The influence of utilizing slag in lieu of fly ash on the performance of engineered cementitious composites, Construction and Building Materials, 2020, 256: 1-11 https://doi.org/10.1016/j.conbuildmat.2020.119412

[35] Chung KL, Xie S, Ghannam M, Guan M, Ning N, Li Y, Zhang C. Strength Prediction and Correlation of Cement Composites: A Cross-Disciplinary Approach. IEEE Access, 2019; 7: 41746-41756 https://doi.org/10.1109/ACCESS.2019.2908042

[36] Sherir MAA, Hossain KMA, Lachemi M. Fresh state, mechanical \& durability properties of strain hardening cementitious composite produced with locally available aggregates and high volume of fly ash. Construction and Building Materials, 2018; 189: 253-264 https://doi.org/10.1016/j.conbuildmat.2018.08.204

[37] ASTM C109. Standard Test Method for Compressive Strength of Hydraulic Cement Mortars (Using 2-in. or [50-mm] Cube Specimens). Annual Book of ASTM Standards, PA, USA; 2012.

[38] ASTM C348 Standard Test Method for Flexural Strength of Hydraulic Cement Mortars Annual Book of ASTM Standards, PA, USA;2008.

[39] Samani SG, Yeganeh AE, Hossain KMA. Prediction of strength properties of engineered cementitious composites using artificial neural network. Proceedings of Annual Conference - Canadian Society for Civil Engineering, Canada, June, 2015. 